\title{
DISCLOSURE VIA WEBSITE CORPORATIVO: UM EXAME DE INFORMAÇÕES FINANCEIRAS E DE GOVERNANÇA NO MERCADO BRASILEIRO
}

DISCLOSURE VIA THE CORPORATE WEBSITE: AN EXAMINATION OF FINANCIAL AND GOVERNANCE INFORMATION IN THE BRAZILIAN MARKET

\section{RESUMO}

Este artigo objetiva analisar a relação entre a disseminação voluntária de informações relevantes nos websites de empresas abertas com suas características, tendo como amostra 282 empresas não financeiras listadas na Bovespa. Com base na relevância de informações corporativas (financeira e de governança) avaliadas pelos intermediários de informações, que embasaram a constituição de índices ponderados de disclosure, os resultados sugerem que há maior disclosure: i) quanto maior a firma e quanto maior o retorno das ações da empresa; ii) em empresas de governança corporativa diferenciada; iii) em categorias de informações corporativas mais requeridas pelas agências de rating e pelas corretoras; iv) em empresas mais endividadas.

\section{Wesley Mendes-da-Silva}

Professor da Fundação Instituto de Administração, Universidade de São Paulo, e do Centro de Ciências Sociais e Aplicadas, Mackenzie - SP, Brasil mr.mendesdasilva@gmail.com

\section{José Mauro Ferraz-Andrade}

Professor da Fundação Instituto de Administração, Universidade de São Paulo, e da Fundação Escola de Comércio Álvares Penteado - SP, Brasil josemaur099@yahoo.com.br

\section{Rubens Famá}

Professor da Faculdade de Economia, Administração e Contabilidade, Universidade de São Paulo - SP, Brasil rfama@usp.br

\section{Jorge Arnaldo Maluf Filho}

Professor do Programa de Pós Graduação em Administração, Universidade de São Paulo - SP, Brasil

jorge.maluf@usp.br

Recebido em 28.03.2007. Aprovado em 17.10.2008

Avaliado pelo sistema double blind review

Editor Científico: Ricardo Ratner Rochman

\begin{abstract}
The objective of this paper is to analyze the relationship between the voluntary disclosures of relevant information on the websites of a sample of 282 non-financial Bovespa-listed publicly-quoted companies. Based on the relevance of the corporate information (financial and governance) assessed by the information intermediaries and that provide the basis for constituting weighted disclosure indices the results suggest that there is more disclosure: i) the bigger the firm is and the bigger the return on company shares; ii) in companies that have a special type of corporate governance; iii) for those categories of corporate information that are more requested by the rating agencies and by stock brokers; iv) in companies with larger debts.
\end{abstract}

PALAVRAS-CHAVE Disclosure, empresas brasileiras, governança corporativa, Internet, relações com investidores. KEYWORDS Disclosure, Brazilian companies, corporate governance, Internet, investor relations. 


\section{INTRODUÇÃO}

Nos últimos vinte anos, a análise das práticas de governança corporativa tem-se tornado um fator-chave para o melhor conhecimento das empresas listadas em bolsas de valores. Ao mesmo tempo, vem sendo apontada como aspecto central para a confiança dos investidores nas decisões dos executivos e conselhos de administração dessas empresas. Adicionalmente, com o advento da internet, as corporações passaram a ter ao seu dispor um inovador e poderoso canal de relacionamento com os investidores (RI). Em mercados mais desenvolvidos que o brasileiro, cada vez mais, as grandes companhias abertas estão utilizando a rede para democratizar o acesso a informações corporativas úteis ao mercado. Com isso, a empresa colabora para a preservação de pelo menos um dos requisitos basilares da boa governança corporativa, a disclosure, além de contribuir para a eficiência do mercado.

Na opinião de autores como Zingales (2000), a influência da mídia deveria ser abordada menos discretamente nas pesquisas desenvolvidas em Economia e Finanças. De maneira complementar, Dyck e Zingales (2002) argumentam que o processo de disclosure ainda tem sido fracamente abordado em modelos econômicos. Por outro lado, um número cada vez maior de pessoas busca informações na mídia, especialmente na internet.

Testemunha-se, então, a necessidade de romper com o padrão anterior de comunicação, inovando o processo de relacionamento com o mercado (BURLAMAQUI e PROENÇA, 2003, p. 83), ainda dominado pela mídia impressa. No âmbito internacional, algumas pesquisas têm abordado as associações entre características corporativas e voluntariedade em disponibilizar, pela internet, informações financeiras ao mercado, destacando-se Brennan e Hourigan (2000) e Schuster e O'Connell (2006). Mas, no caso brasileiro, a falta de padronização do uso da internet para atividades de RI tem possibilitado uma variedade de formas de exploração da rede para a comunicação com o mercado (MENDES-DA-SILVA e MAGALHÃES FILHO, 2005a).

O objetivo desta pesquisa é verificar a existência de associações entre as características das empresas (alavancagem, retorno anual das ações, tamanho, rentabilidade e tempo de listagem em bolsa) e a disseminação voluntária de informações de interesse do investidor (informações financeiras e de governança corporativa), por meio de websites corporativos. O estudo desenvolve-se com base em todas as empresas não financeiras listadas na Bovespa, no último bimestre de 2005.
A contribuição principal deste trabalho está centrada em um melhor entendimento dos determinantes da disclosure de informações úteis ao investidor, já que oferece uma estrutura para a análise das práticas de disclosure voluntária utilizadas pelas empresas. E ainda contribui para o desenvolvimento dessa área de conhecimento, possuindo aplicabilidade prática para a solução de problemas reais (Wacker, 1998, p. 361). Ademais, a consideração das preferências dos intermediários de informações corporativas na construção de índices ponderados de disclosure corporativa constitui uma contribuição adicional.

Este artigo está organizado em cinco partes. A seção 2 apresenta a literatura relevante acerca da temática. Em seguida, na seção 3, são detalhadas as hipóteses testadas. A seção 4 relata a metodologia adotada para a realização da pesquisa. Logo após, na seção 5 , são apresentados e discutidos os resultados empíricos alcançados no estudo, e na seção 6, desenvolvem-se as considerações finais.

\section{REVISÃO DA LITERATURA}

Segundo La Porta e outros (1998), na América Latina ainda são incipientes a discussão e a elaboração de políticas de gerenciamento, orientadas por princípios de governança corporativa, apesar de já existirem iniciativas de diversos setores da sociedade com vistas à sua difusão e valorização no âmbito das economias emergentes. Na experiência brasileira, no que se refere ao incentivo à adoção de boas práticas de governança, destacam-se as iniciativas do Instituto Brasileiro de Governança Corporativa (IBGC), da Comissão de Valores Mobiliários (CVM) e da Bolsa de Valores de São Paulo.

Contudo, o uso do website corporativo para RI, por parte das empresas, ainda é voluntário. De maneira complementar, tanto na literatura acadêmica como na gerencial, é possível constatar o crescente interesse pela matéria deste artigo. Assim, Isenmann e Lenz (2001) defendem que o incremento da procura pelo acesso à informação tornou imperativo o uso de novas plataformas de comunicação, destacadamente a internet.

A utilização de tecnologias inovadoras tem um impacto significativo na disponibilidade e na difusão de informações, introduzindo vantagens para as empresas como: redução do custo de comunicação, aumento da velocidade de troca de informações, redução do esforço administrativo e versatilidade no manuseio de conteúdos interessantes ao mercado, permitindo a realização de operações até então inviáveis ou mesmo impossíveis (WAGENHOFER, 2003, p. 265; SCHUSTER e CONNELL, 2006, p. 5). 
Rocca e Carvalho (1999), ao consultarem empresas de capital aberto no Brasil, identificaram o custo de manutenção como o aspecto mais representativo entre as desvantagens da listagem em bolsa. E mais, na composição dos custos de manutenção em bolsa, as despesas com publicações são o segundo fator mais representativo. Então, parece razoável supor que reduzir os custos de manutenção em bolsa via custos de publicação contribui para aumentar o interesse das empresas pelo mercado de capitais.

Embora já exista, ao redor do mundo, uma quantidade razoável de estudos relacionados aos fatores determinantes da disseminação voluntária de informações de interesse do investidor pela internet, no Brasil essa questão ainda é pouco explorada. Litan e Wallison (2000, p. 8) ressaltam a preocupação dos mercados mais desenvolvidos com esse aspecto. Assim, tanto pelo lado da demanda quanto pelo lado do fornecimento de informações, as implicações da internet são profundas. Isto é, se as empresas podem utilizar a rede para acessar informações e mercados, de forma quase instantânea e constante, e tanto investidores como analistas são ávidos por informações, o resultado óbvio é o aumento da disponibilização de informações do interesse dos investidores via website corporativo. Para Schuster e Connell (2006, p. 2), o desenvolvimento de disclosure voluntária pode trazer vantagens, dada a capacidade de redução da assimetria de informações entre acionistas e gestores, o que pode ser potencializado pelo uso do website corporativo para RI.

Por outro lado, para Wagenhofer (2003, p. 263), apesar da maior aceitação e das possibilidades de disclosure pelo website, a maioria das informações disponibilizadas pelas empresas ainda é a mesma apresentada por fontes tradicionais de informação. O mesmo autor argumenta que algumas empresas ainda não estão sendo suficientemente hábeis no aproveitamento das potencialidades da nova tecnologia, principalmente no que diz respeito à maior interação com os investidores.

Contudo, há problemas associados ao uso da internet, já que a padronização quase inexiste. Em alguns países já há algumas tentativas de inserir orientações para a disseminação de informações para investidores pelo website, sendo contemplados essencialmente: (a) a autenticidade e a credibilidade das informações financeiras e ainda os relatórios divulgados pelos auditores (DEBRECENY e GRAY, 1999); (b) a segurança e a coerência entre relatórios financeiros estatutários e outras informações financeiras on-line (KORETO, 1997); e (c) o esmero dos auditores em relação aos relatórios on-line (SHEEHY e TRITES, 1997). Mas as companhias possuem diferentes políticas e práticas no uso da rede para atividades de RI. Então, em 1996, nos Estados Unidos, no ambiente empresarial, surgia o EDGAR (Electronic Data Gathering, Analysis, and Retrieval), uma tentativa de padronizar procedimentos. Enquanto no Canadá era criado o SEDAR (System for Electronic Document Analysis and Retrieval). Ainda nesse contexto, pode-se citar o XBRL (eXtensible Business Reporting Language) como uma linguagem de extensão do XML (eXtensible Markup Language) para uso na apresentação e intercâmbio de informações, principalmente as financeiras e contábeis.

$\mathrm{Na}$ comunidade acadêmica, o interesse não é menor. Gray e Debreceny (1997) examinaram empresas norteamericanas e concluíram que mais de $60 \%$ delas utilizam a rede para disseminação de informações financeiras. $\mathrm{Na}$ Finlândia, Lymer e Tallberg (1997) encontraram resultados similares. Porém, na Espanha, Gowthorpe e Amat (1999) identificaram somente 19\% de empresas adotantes dessa prática. Mas também existem investigações que vão além da simples disponibilização dos relatórios financeiros.

O relacionamento com investidores pela rede foi objeto de pesquisa realizada por Heldin (1999), o qual concluiu que, na Suécia, apesar de 83\% das empresas divulgarem informações no website, somente uma minoria delas o fazia de forma estruturada, oferecendo informações julgadas relevantes, em tempo real. No Reino Unido, Marston e Leow (1998) concluíram que o tamanho da firma está positivamente associado à disponibilização de informações financeiras no website corporativo. Porém, essa associação não foi uniforme entre os diversos setores industriais considerados nessa pesquisa, corroborada pelo trabalho de Craven e Marston (1999).

Alguns estudos, como os de Isenmann e Lenz (2000), Kolk (1999), Jones, Alabaster e Hetherington (1999), atestam que, na América Latina, os relatórios disponíveis eram dominados por publicações em mídia impressa. Contudo, de maneira geral, tem sido observada uma tendência crescente do uso da internet. Ademais, no Brasil, segundo resultados obtidos por Mendes-Da-Silva (2006), o nível de divulgação de informações financeiras pelas empresas listadas na Bovespa, nos últimos três anos, tem aumentado. Isso não supõe necessariamente um alinhamento com as demandas de informações corporativas que o mercado mantém.

Já é possível encontrar um conjunto numeroso de pesquisas acerca da disclosure corporativa no Brasil, um dos primeiros é o de Rocha e Procianoy (2004). Especificamente com respeito à abordagem do uso do website corporativo para esse fim, ainda é pequena a produção científica a partir do mercado brasileiro. Destacandose como uma das primeiras tentativas as pesquisas de 
Mendes-Da-Silva e Magalhães Filho (2005a e 2005b), que consideram empresas não financeiras listadas em 2002 na Bovespa, essas encontraram associação positiva entre tamanho da empresa e soma de informações financeiras no website e, também, associação negativa do retorno das ações com a soma de informações financeiras no website corporativo.

Mendes-Da-Silva e Magalhães Filho (2005b) concluíram que as empresas manufatureiras listadas na Bovespa, cujo presidente do conselho de administração não exerce atividades simultâneas na diretoria executiva (assumida como um outsider), são mais propensas a divulgar informações financeiras pelo website. Segundo esses autores, nos países latino-americanos, especialmente em função da percepção de risco no mercado de ações (entre investidores), muitas empresas ainda não conseguem obter valorização adequada. A principal razão para isso seria a falta de transparência e de garantias aos investidores, assim como a ineficiência do mercado (inclusive assimetria informacional).

Esse fenômeno verifica-se em um estudo da McKinsey \& Company (2000), no qual se afirma que $83 \%$ dos investidores internacionais possuidores de recursos aplicados na América Latina estariam dispostos a pagar um prêmio por empresas que sejam visivelmente bem governadas. Se o conhecimento e a aplicação de boas práticas de governança corporativa são aspectos críticos, a forma como a empresa divulga suas práticas não é menos importante. Desse modo, para aumentar a credibilidade junto aos participantes do mercado, além dos aspectos puramente financeiros, as empresas necessitam tornar as informações referentes à sua administração rapidamente acessíveis, focando seus esforços no fornecimento de uma mensagem clara e concisa, da maneira mais transparente possível, conforme recomendado, por exemplo, no Report of the High Level Group of Company Law Experts (2002, p. 33-34).

\section{HIPÓTESES}

Para Leftwich, Watts e Zimmerman (1981), a relação entre fornecedores externos de capital (principais) e os gerentes (agentes) da firma é um exemplo de relação de agência (Jensen e Meckling, 1976), sugerindo que os custos de agência do capital emprestado dependem dos objetivos dos fornecedores externos. Isso indica que os custos seriam mais altos para as firmas com maior alavancagem. Adicionalmente, a disclosure poderia reduzir os custos de agência, por facilitar a avaliação da habilidade da firma em contrair endividamento.
Enquanto alguns estudos revelaram relação positiva entre disclosure e alavancagem financeira (MITCHELL, CHIA e LOH, 1995; HOSSAIN, BERERA e RAHMAN, 1995), outros não apoiam esses resultados. Assim, Mckinnon e Dalimunthe (1993), Aitken, Hooper e Pickering (1997) e Brennan e Hourigan (2000) não encontraram relação positiva significativa entre alavancagem e o nível de disclosure financeira e até mesmo sugerem que essa relação seja negativa (MEEK, ROBERTS e GRAY, 1995). Os resultados oferecidos por esses estudos são inconclusivos. Dessa forma, testa-se neste artigo a relação entre alavancagem e disclosure de informações no website corporativo; a primeira hipótese então é:

$\mathrm{H}_{1}$ : A alavancagem financeira da firma não está associada à quantidade de informações de interesse do investidor disseminadas no website corporativo.

Todavia, os investidores geralmente percebem a ausência de disseminação voluntária de informações como um indicador de más notícias sobre uma firma. Assim, empresas cuja gestão atua de forma a aumentar o valor de suas ações acima da média de mercado teriam um incentivo adicional para disseminar informações voluntariamente (LEV e PENMAN, 1990; LANG e LUNDHOLM, 1993; CLARKSON, KAO e RICHARDSON, 1994). Desse modo, a segunda hipótese deste estudo é:

$\mathrm{H}_{2}$ : A quantidade de informações do interesse do investidor disponíveis no website da firma é positivamente relacionada ao retorno das ações da firma.

A literatura na área de administração fornece amplamente argumentos que defendem a ideia de que as empresas de maior porte tendem a adotar práticas de gestão mais profissionais, tendo em vista a maior complexidade organizacional. Nesse contexto, Cox (1985), Waymire (1985), Lang e Lundholm (1993), Clarkson, Kao e Richardson (1994), Marston e Leow (1998), entre outros, encontraram uma associação positiva entre tamanho da firma e a quantidade de disseminação voluntária. A terceira hipótese formulada então é:

$\mathrm{H}_{3}$ : A quantidade de informações de interesse do investidor disseminadas no website é positivamente relacionada ao tamanho da firma.

Na ótica de Haniffa e Cooke (2002), o gerente poderia ser encorajado a divulgar mais informações de interesse do investidor quando as taxas de rentabilidade são altas, 
expressando a boa qualidade da administração. Porém, segundo evidenciam os resultados obtidos por Ashbaugh, Johnstone e Warfield (1999), a relação entre rentabilidade e a disseminação de informações seria insignificante. Sendo os resultados das pesquisas nesse campo inconclusivos, a quarta hipótese a ser testada é:

$\mathrm{H}_{4}$ : A rentabilidade da empresa não está associada à disseminação de informações de interesse do investidor no website.

Já para Haniffa e Cooke (2002), uma empresa mais recentemente listada na bolsa teria um incentivo adicional para oferecer voluntariamente mais informações, com o intuito principal de combater o ceticismo em relação à firma e angariar a confiança dos investidores. Então, propõe-se uma quinta e última hipótese:

$\mathrm{H}_{5}$ : A soma de informações de interesse do investidor divulgadas por uma firma em seu website está negativamente associada ao seu tempo de listagem em bolsa.

\section{METODOLOGIA}

\section{Construção dos índices de disclosure}

Após examinada a literatura, e a partir da exploração de cada website corporativo, foram buscadas 37 categorias de informações de interesse do investidor, agrupadas em dois blocos: um com 17 de natureza financeira (I_Fin) e outro de 20 categorias relativas à governança (I_Gov), que possibilitaram a constituição de um índice de disclosure corporativo (I_Disc), conforme ilustra a Tabela 1 .

Os aspectos examinados nos websites são os mais frequentemente abordados na literatura. Não somente nos âmbitos nacional e internacional, não foram encontrados estudos que considerassem a relevância das informações corporativas para os intermediários de informações, tais como agências de classificação de risco (rating) e corretoras de valores mobiliários. Isso pode conferir às métricas de disclosure algum viés, considerando a atenção que a gestão da empresa dispensa à divulgação das diversas informações, uma vez que pode não estar alinhada com sua relevância, segundo a ótica dos usuários de informações corporativas.

Para contemplar o interesse dos intermediários de informações, foi conduzida uma verificação, no mês de janeiro de 2006 (época do desenvolvimento deste trabalho), da relevância das categorias de informações corporativas junto às agências de rating e corretoras de valores mobiliários. Para tanto, foram remetidos convites a todas as corretoras cadastradas junto à Bolsa de Valores de São Paulo, além das agências de rating em atuação no Brasil. Em consequência, foram recebidas 13 opiniões de intermediários, sendo: 4 de agências de rating e 9 de corretoras. A consulta a esse público foi operacionalizada com o emprego de uma página disponibilizada na web.

As categorias de informações corporativas consideradas, apresentadas na Tabela 1 , foram agregadas em dois subgrupos, que proporcionaram a obtenção de dois índices parciais: i) informações financeiras (I_Fin), baseadas nas utilizadas por Mendes-Da-Silva e Magalhães Filho (2005a); e ii) práticas de governança corporativa adotadas pela empresa (I_Gov). A junção desses dois índices resulta num terceiro, o índice de disclosure total (I_Disc).

Estudos anteriores, como o de Mendes-Da-Silva e Magalhães Filho (2005a), apesar de reconhecerem a relevância assimétrica de cada tipo de informação corporativa (BOTOSAN, 1997), atribuem o mesmo peso para todas as categorias de informação, considerando informações essencialmente financeiras. Diante disso, neste estudo, adotou-se o procedimento de aferir a relevância atribuída às informações corporativas disponibilizadas, conforme consulta aos intermediários financeiros anteriormente mencionada.

Para a atribuição dessas notas às informações de cada empresa, os dados necessários à obtenção das variáveis dependentes foram baseados na visitação de cada website, durante o mês de dezembro de 2005, duas vezes por pesquisadores diferentes. As duas informações para cada empresa foram comparadas e as diferenças de julgamento (quando existentes) reconciliadas com um novo acesso ao website. Cada um dos três índices de disclosure, para uma $n$-ésima firma, foi obtido pela soma das notas atribuídas para cada j-ésima categoria de informação, conforme as equações (1), (2), (3).

$$
I_{-} \operatorname{Fin}_{n}=\sum_{j=1}^{17} p_{j}
$$

Onde:

$p_{j}=\sum_{i=1}^{13} a_{i}$, sendo $a_{i}$ a nota atribuída por um i-ésimo respondente dentre os treze intermediários de informações corporativas consultados na pesquisa, a cada uma das 17 categorias $p_{j}$ de informação de natureza financeira, podendo cada nota atribuída variar de 0 a 4 . O índice 
WESLEY MENDES-DA-SILVA · JOSÉ MAURO FERRAZ-ANDRADE · RUBENS FAMÁ · JORGE ARNALDO MALUF FILHO

Tabela 1 - Lista e frequência alcançada pelas categorias de informações de interesse do investidor nos websites corporativos

\begin{tabular}{|c|c|c|c|}
\hline & CATEGORIAS & FREQ. & $(\%)$ \\
\hline \multirow{18}{*}{ 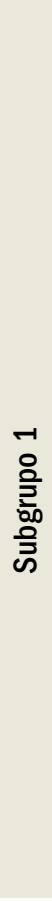 } & Informações financeiras (I_Fin) & & \\
\hline & 1. Relatório anual completo & 163 & 57,8 \\
\hline & 2. Relatórios trimestrais incluindo relatórios financeiros & 145 & 51,4 \\
\hline & 3. Outros arquivos da CVM além dos relatórios anuais (Relatório de Informações Anuais-IAN, por exemplo) & 109 & 38,7 \\
\hline & 4. Link para o website da Comissão de Valores Mobiliários - CVM & 50 & 17,7 \\
\hline & 5. Texto das notícias financeiras mais recentes & 118 & 41,8 \\
\hline & 6. Visão geral consistente do desempenho da firma (perguntas mais frequentes, fatos recentes, notícias rápidas) & 112 & 39,7 \\
\hline & 7. Informações financeiras em outro idioma além do português & 95 & 33,7 \\
\hline & 8. Histórico dos preços das ações & 91 & 32,3 \\
\hline & 9. Preços atuais das ações da empresa nos mercados onde tem ações negociadas & 90 & 31,9 \\
\hline & 10. Textos de comentários e apresentações (por exemplo, os road shows do desempenho trimestral) & 87 & 30,9 \\
\hline & 11. Discussão das vantagens de um investidor em manter a posse das ações da empresa & 70 & 24,8 \\
\hline & 12. Calendário de eventos de interesse do investidor (por exemplo, a data de distribuição dos dividendos) & 69 & 24,5 \\
\hline & 13. Link para os dados das ações em um website diferente & 63 & 22,3 \\
\hline & 14. Cobertura de analistas & 49 & 17,4 \\
\hline & 15. Informação sobre a(s) sua(s) corretora(s) (endereço ou link direto) & 32 & 11,3 \\
\hline & 16. Dados financeiros mensais mais recentes & 26 & 9,2 \\
\hline & 17. Informações detalhando um plano de reinvestimento de dividendos & 19 & 6,7 \\
\hline \multirow{21}{*}{ 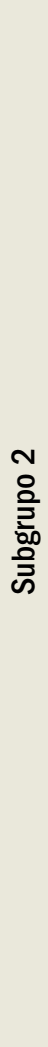 } & Governança corporativa (I_Gov) & & \\
\hline & 1. Relatórios de responsabilidade social empresarial & 133 & 47,2 \\
\hline & 2. Identidade dos membros do conselho de administração & 88 & 31,2 \\
\hline & 3. Estrutura do conselho de administração & 80 & 28,4 \\
\hline & 4. Composição acionária da empresa & 80 & 28,4 \\
\hline & 5. Política de disseminação de informações nos mercados & 60 & 21,3 \\
\hline & 6. Texto acerca do conceito de governança corporativa & 59 & 20,9 \\
\hline & 7. Referência às boas práticas de governança corporativa adotadas & 57 & 20,2 \\
\hline & 8. Qualificação profissional de diretores e conselheiros & 55 & 19,5 \\
\hline & 9. Onde a empresa está listada e relatórios financeiros segundo padrões nacionais & 45 & 16,0 \\
\hline & 10. Regra de conduta para diretores & 37 & 13,1 \\
\hline & 11. Procedimento para seleção e eleição de diretores e conselheiros & 35 & 12,4 \\
\hline & 12. Publicação da função e escritório dos diretores & 32 & 11,3 \\
\hline & 13. Regras de funcionamento do conselho de administração & 30 & 10,6 \\
\hline & 14. Descrição das condições de independência dos conselheiros & 21 & 7,4 \\
\hline & 15. Remuneração dos diretores e dos conselheiros & 20 & 7,1 \\
\hline & 16. Descrição explícita dos poderes dos diretores & 18 & 6,4 \\
\hline & 17. Descrição das relações entre diretores e acionistas & 15 & 5,3 \\
\hline & 18. Divulgação dos escritórios de diretores em outras empresas & 13 & 4,6 \\
\hline & 19. Interesses dos diretores em parcela do capital da empresa & 6 & 2,1 \\
\hline & 20. Taxas pagas às firmas de auditoria & 2 & 0,7 \\
\hline
\end{tabular}

Nota: $\mathrm{N}=282$. Os dados resumidos nesta tabela foram agregados na formação dos dois subgrupos ilustrados nas equações (1) e (2). A metodologia consiste em: para cada item presente em um website corporativo, dentre os citados nesta tabela, a empresa recebe a pontuação $p_{j}$ ou $q_{k}$, as quais, quando somadas conforme equações (1) e (2), serviram para compor os índices: I_Fin, I_Gov, e I_Disc. 
de disclosure de informações de governança corporativa I_Gov foi calculado da seguinte maneira:

$$
I_{-} G o v_{n}=\sum_{k=1}^{20} q_{k}
$$

Onde:

$q_{k}=\sum_{i=0}^{13} a_{i}$, sendo $a_{i}$ a nota atribuída por um i-ésimo respondente, dentre os treze intermediários de informações corporativas, consultado na pesquisa, a cada uma das 20 categorias $q_{k}$ de informações relativas à governança, podendo cada nota atribuída variar de 0 a 4 . Por fim, a equação (3) apresenta a junção dos dois primeiros índices para a formação do índice de disclosure total (I_Disc):

$$
I_{-} \text {Disc }_{n}=I_{-} \text {Fin }_{n}+I_{-} G o v_{n}=\sum_{j=1}^{17} p_{j}+\sum_{k=1}^{20} q_{k}
$$

Tendo em vista que cada uma das 37 categorias de informações corporativas está ponderada pela relevância identificada junto aos intermediários de informações corporativas, o fato de uma empresa deixar de oferecer em seu website, por exemplo, o relatório anual da administração constitui uma falta mais grave que omitir um calendário de eventos, tendo em vista que o primeiro possui maior relevância para os intermediários que o último. O con- junto final de empresas estudadas foi composto de 282 firmas, distribuídas entre 19 setores de atividade, como ilustra a Tabela 2.

Mendes-Da-Silva (2006) assumiu que as categorias de informações financeiras, bem como as de governança, mais frequentemente disponibilizadas deveriam ser as mais relevantes para os usuários de informações corporativas. No entanto, ao menos à luz da opinião dos intermediários de informações aqui consultados, essa premissa não parece razoável. Isto é, conforme ilustram as Figuras 1 e 2 (informações financeiras e de governança, respectivamente), as categorias mais representativas para os respondentes parecem não alcançar um nível de disseminação adequado. Por outro lado, a diferença entre a relevância para os usuários e a disponibilização por parte das empresas, em se tratando de categorias menos relevantes, parece ser menor. Com esse comportamento, as empresas revelam uma atitude de disponibilizar, mais frequentemente, aspectos menos relevantes para os intermediários de informações corporativas.

Na Figura 1 nota-se, por exemplo, que o esclarecimento das políticas de reinvestimento da empresa recebe atenção especial dos intermediários de informações, enquanto poucas empresas se mostraram dispostas a entregar essas informações. Já na Figura 2, pode-se verificar o aparente atendimento insuficiente da demanda do mercado por informações que contribuam para a elucidação das questões

Tabela 2 - Conjunto de empresas estudadas (por setores da economia)

\begin{tabular}{|l|c|l|c|}
\hline \multicolumn{1}{|c|}{ SETOR } & FREQUÊNCIA $(\%)$ & \multicolumn{1}{c|}{ SETOR } & FREQUÊNCIA (\%) \\
\hline Outros & $46(16,3)$ & Construção & $11(3,9)$ \\
\hline Energia Elétrica & $38(13,5)$ & Papel e Celulose & $8(2,8)$ \\
\hline Siderurgia e Metalurgia & $28(9,9)$ & Petróleo e Gás & $7(2,5)$ \\
\hline Têxtil & $26(9,2)$ & Eletroeletrônicos & $6(2,1)$ \\
\hline Telecomunicações & $20(7,1)$ & Máquinas Industriais & $4(1,4)$ \\
\hline Química & $19(6,7)$ & Minerais não Metálicos & $4(1,4)$ \\
\hline Alimentos e Bebidas & $17(6,0)$ & Agropecuária e Pesca & $3(1,1)$ \\
\hline Veículos e peças & $15(5,3)$ & Mineração & $3(1,1)$ \\
\hline Comércio & $14(5,0)$ & Software e Dados & $1(0,4)$ \\
\hline Transporte e Serviços & $12(4,3)$ & Total & $282(100)$ \\
\hline
\end{tabular}

Nota: A classificação dos setores deu-se segundo critérios da Economatica ${ }^{\circledR}$.

Das 484 empresas listadas na Bolsa de Valores de São Paulo (Bovespa) em dezembro de 2005, foram consideradas as 434 empresas não financeiras (as 50 empresas financeiras listadas foram excluídas, por trabalharem essencialmente alavancadas), das quais: 37 não mantinham website, ou esse não foi encontrado no banco de dados da Economatica ${ }^{\circledast}$, tampouco no site de busca utilizado, o http://www.google.com; e 115 empresas não possuíam os dados necessários para operacionalizar as variáveis independentes utilizadas, no banco de dados da Economatica ${ }^{\circledR}$, resultado no conjunto final de 282 empresas a estudar. 
ao redor do tema dos interesses dos diretores em parte do capital da firma.

A seguir, na Tabela 3, podem ser observadas as definições adotadas para as variáveis independentes utilizadas nesta pesquisa, as quais incluem tanto medidas contábeis (efeito endógeno) quanto medidas de mercado (efeito exógeno). Entre as variáveis independentes, o nível de participação de capitais de terceiros foi calculado a partir da alavancagem financeira da empresa, Alav. A performance da empresa foi medida pelo retorno anual das ações mais líquidas da empresa, Retn. O tamanho da firma, lnTamf, foi mensurado pelo logaritmo natural do valor contábil do ativo total da firma i. A variável Roa é indicada pela rentabilidade do ativo total de uma empresa $i$. A variável $\ln$ Temp foi dada pelo logaritmo natural do tempo, em anos, que a empresa está listada na Bovespa.

As variáveis de controle $(V C)$ foram selecionadas com base na possível influência que exercem sobre as variáveis dependentes de divulgação voluntária de informações de interesse do investidor na internet (I_Fin, I_Gov, I_Disc) e independentes (Alav, Retn, $\operatorname{lnTamf}$, Roa, e $\ln$ Temp). Caso as variáveis de controle possuam forte correlação com algumas dessas variáveis e não sejam consideradas no modelo, a relação entre as variáveis de interesse pode não ser evidenciada de forma adequada. Assim, as seguintes variáveis de controle foram utilizadas: Liqb; Hpod; Q; e Ngc.

\section{Regressão}

Para testar as hipóteses propostas, foram utilizadas três variáveis para medir a divulgação voluntária de informações de interesse do investidor (dependente): I_Fin, I_Gov, I_Disc, conforme ilustram as equações (4), (5) e (6), respectivamente. Para verificar as associações entre características corporativas e disseminação voluntária de informações de interesse do investidor, foram empregadas cinco variáveis independentes, uma para cada hipótese proposta: Alav, Retn, $\operatorname{lnTamf}$, Roa e $\operatorname{lnTemp}$, além

Figura 1 - Comparação da relevância das categorias de informação financeira e disponibilização por parte das empresas listadas

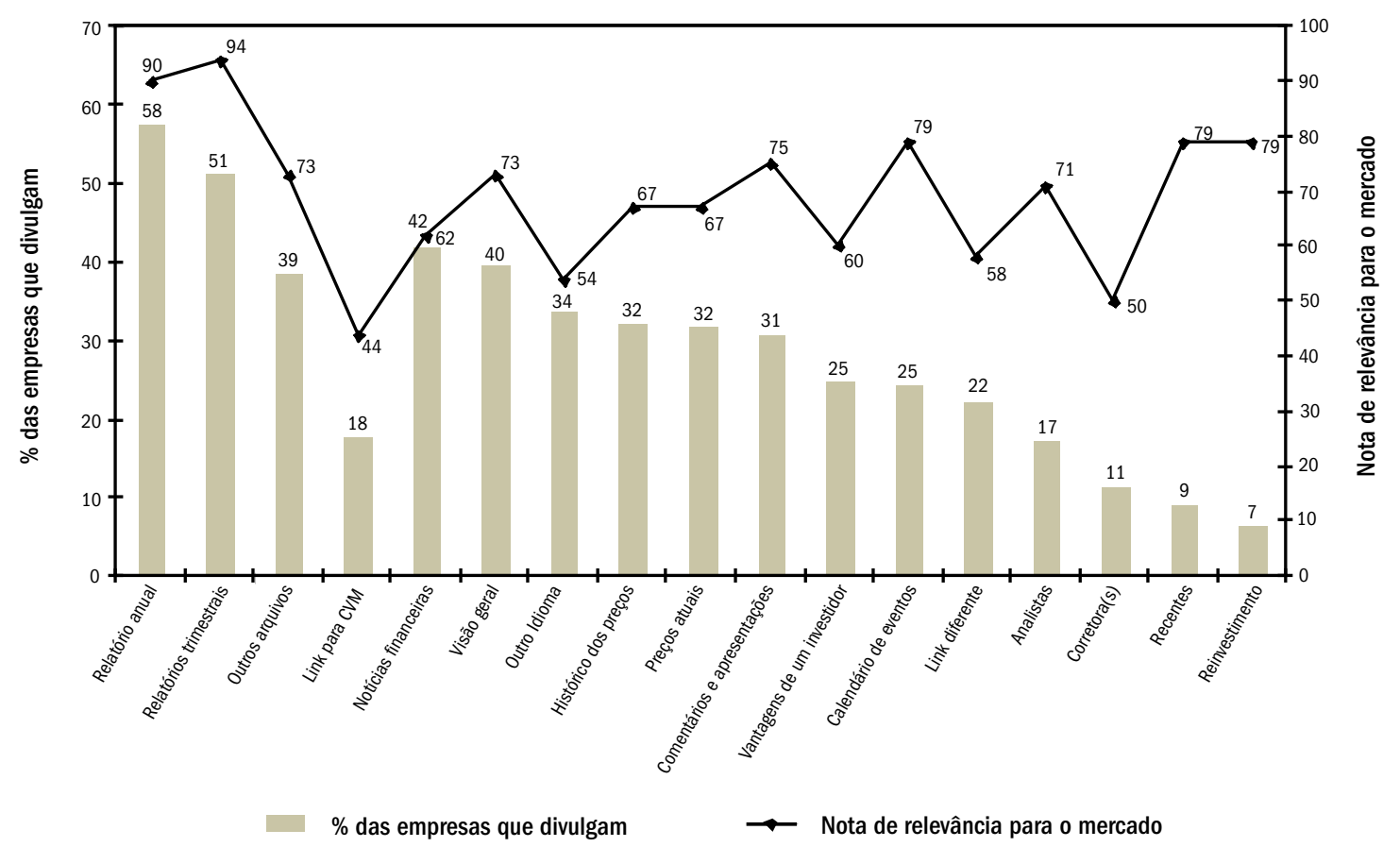

Nota: Esta figura ilustra a comparação da relevância das informações financeiras e disponibilização por parte das empresas listadas. Para tanto, são confrontadas a proporção das empresas que disponibilizam as categorias de informações pesquisadas; com a pontuação relativa (em forma percentual) do máximo de pontos que as categorias poderiam alcançar mediante avaliação de relevância na ótica dos intermediários de informações corporativas consultados (13 profissionais atribuíram notas de 0 a 4 para cada categoria de informação corporativa). Desse modo, nota-se que a relevância das informações (representadas pelas barras verticais) parece não estar se refletindo no que é oferecido pelas empresas em seus websites corporativos. Ou seja, parece que as informações mais requeridas pelos intermediários são justamente aquelas encontradas com menor frequência nos websites das empresas. 
Figura 2 - Comparação da relevância das categorias de informação de governança corporativa e disponibilização por parte das empresas listadas

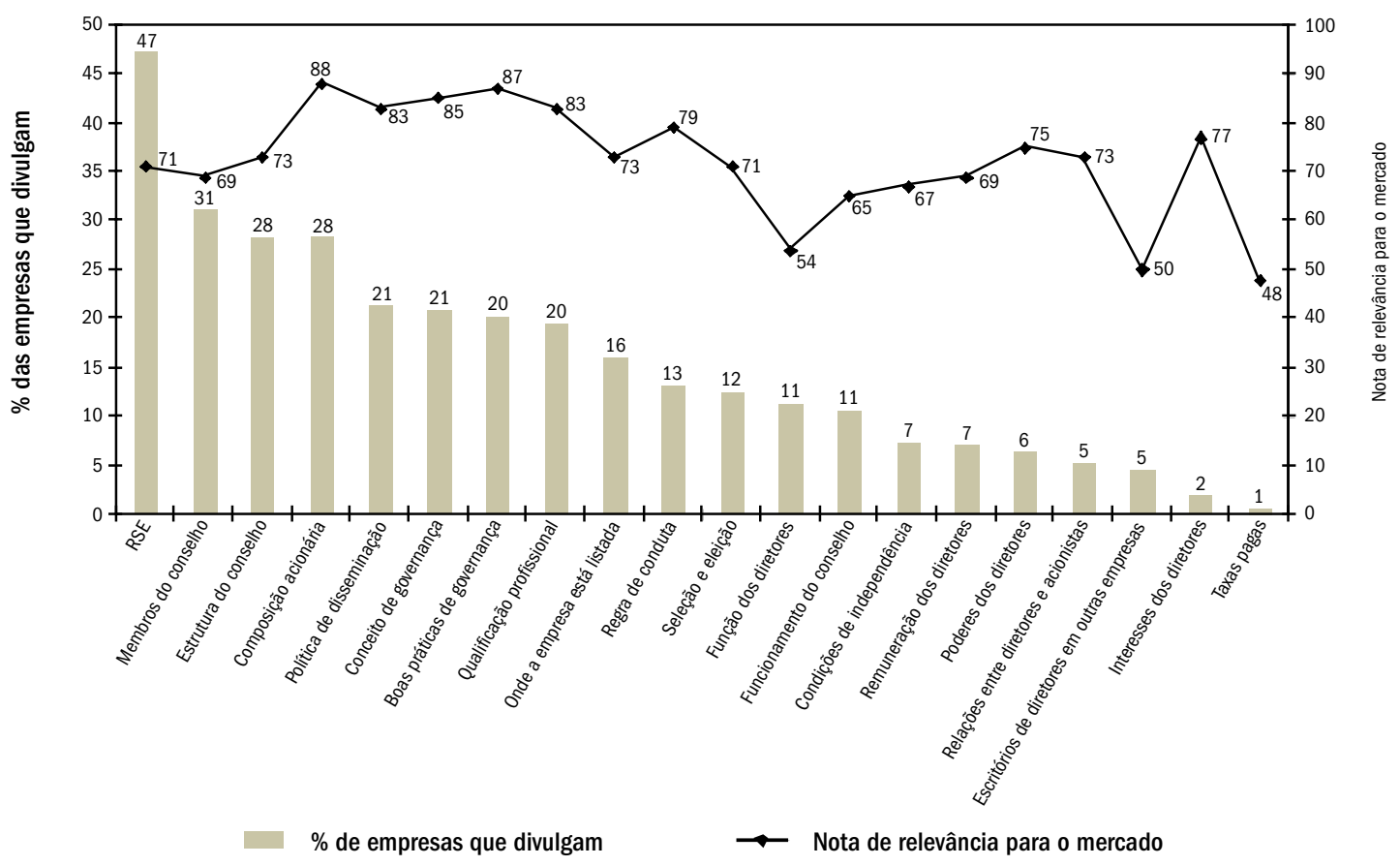

Nota: Esta figura ilustra a comparação da relevância das categorias de informações relativas à governança corporativa e disponibilização por parte das empresas listadas na Bovespa. A interpretação desta ilustração é similar àquela construída para a Figura 1. Ou melhor, parece haver alguma assimetria entre preferências do mercado e propensão das empresas a entregar informações voluntariamente por meio de seu website corporativo.

das variáveis de controle consideradas. A utilização de variáveis contábeis e de mercado visa contemplar motivações de caráter endógeno e exógeno, para que a firma dissemine, voluntariamente, informações de interesse do investidor.

\section{RESULTADOS ALCANÇADOS}

Com a intenção de testar as hipóteses adotadas neste estudo, foi utilizado o procedimento da regressão múltipla pelo método Enter (todas as variáveis independentes são colocadas em um só bloco, ao mesmo tempo, na estimativa dos parâmetros da regressão), conforme Hair e outros (1998). Desse modo, foram testados cinco modelos para cada uma das três variáveis de disclosure (I_Fin; I_Gov; I_Disc). Então, partindo-se das variáveis de interesse, foram

Os modelos (4), (5) e (6) possuem variáveis independentes defasadas de um período. Esse procedimento visa verificar se as características anteriores da firma exercem influência sobre o nível de divulgação financeira. acrescentadas as VC (Liqb, Hpod, Q, Ngc) progressivamente no modelo principal (Modelo 1). Com esse procedimento, esperou-se verificar se as significâncias encontradas se manteriam após a introdução das VC. 
Tabela 3 - Definição das variáveis independentes utilizadas

\begin{tabular}{|c|c|}
\hline VAR & DES \\
\hline Alav* & $\begin{array}{l}\text { Alavancagem financeira de uma empresa } i \text { no ano } t-1 \text { calculada segundo a expressão: } \\
\qquad \operatorname{Alav}_{t-1}=\frac{L L}{P L} /\left[\frac{(L L-R F)}{A T}\right] \\
\text { onde: } \mathrm{LL}=\text { Lucro líquido; } \mathrm{PL}=\text { Patrimônio Líquido; } \mathrm{RF}=\text { Resultado financeiro; } \\
\qquad \mathrm{AT}=\text { valor contábil do ativo total }\end{array}$ \\
\hline Retn* & $\begin{array}{l}\text { Retorno anual oferecido pelas ações mais líquidas da empresa } i \text { no ano } t-1 \text {, calculado pela } \\
\text { expressão: } \\
\qquad \operatorname{Re} t n_{t-1}=\left[\frac{P_{f}-P_{i}+\text { Dividendos }}{P_{i}}\right] \times 100 \\
\text { onde: } P_{f}=\text { cotação da ação no último pregão do ano } t-1 . \\
\qquad P_{i}=\text { cotação da ação no primeiro pregão do ano } t-1 .\end{array}$ \\
\hline InTa & $\begin{array}{l}\text { Logaritmo natural do valor contábil do ativo total da empresa } i \text { no ano } t-1 \text {, expresso em } \\
\text { milhares de Reais. }\end{array}$ \\
\hline
\end{tabular}

Retorno do Ativo Total da empresa $i$ no ano $t$-1. Calculado segundo a expressão:
Roa*

InTemp*

Liqb*

Q*

$\mathrm{NgC}^{* *}$

$$
\operatorname{Roa}_{t-1}=\frac{L A J I R}{A T}
$$

onde: $L A J I R=$ lucro antes dos juros e impostos

$A T=$ valor contábil do ativo total

Logaritmo natural da quantidade de anos em que a empresa está listada na Bovespa (até dezembro de 2005).

Liquidez em bolsa calculada pela expressão:

$$
L i q b_{t-1}=\frac{100 p \sqrt{n v / N V}}{P}
$$

onde: $p=$ número de dias em que houve ao menos um negócio com a ação de um período escolhido; $P=$ número total de dias do período escolhido; $n=$ número de negócios com a ação dentro de um período; $N$ = número de negócios com todas as ações dentro de um período; $v$ = volume de dinheiro com a ação dentro do período escolhido; $V=$ volume de dinheiro com todas as ações dentro do período escolhido.

$\mathrm{Hpod}^{*}$

Índice Herfindahl-Hirschman da concentração do poder de voto da empresa i, calculado a partir do percentual das ações ordinárias em poder de cada um dos três principais acionistas.

Índice $Q$ de Tobin, medida de valor de mercado da companhia que é calculado pela expressão:

$$
Q_{t-1}=\left[\frac{V M O+V M A P+D I V T}{A T}\right]
$$

onde: $V M O=$ Valor de Mercado das ações Ordinárias; $V M A P=$ Valor de Mercado das Ações Preferenciais; $D I V T=$ valor contábil das dívidas de curto e longo prazo menos o ativo circulante, após a exclusão do valor dos estoques; $A T$ = valor contábil do ativo total

Variável dicotômica que expressa se a empresa encontra-se listada nos Níveis de Governança Corporativa da Bovespa. Recebeu valor = 1 se pertence ao Novo Mercado, Nível 1 ou Nível 2; e valor $=0$ no caso alternativo.
FONTES CONCEITUAIS

Mckinnon e Dalimunthe (1993); Michell, Chia e Loh. (1995); Meek, Roberts e Gray (1995); Hossain, Berera e Rahman (1995)

Lev e Penman (1990); Lang e Lundholm (1993); Clarkson, Kao e Richardson (1994); Ettredge, Richardson e Scholz (2002)

Cox (1985);

Waymire (1985).

Haniffa e Cooke (2002); Ashbaugh, Johnstone e Warfield (1999)

Haniffa e Cooke (2002)

Mendes-Da-Silva e Magalhães Filho (2005a)

Mendes-Da-Silva (2006)

Chung e Pruitt (1994)

Mendes-Da-Silva e Magalhães Filho (2005a)

Fonte operacional: (*) Banco de dados da Economatica ${ }^{\oplus}$. (**) Boletim Diário de Informações (BDI)/Bovespa, n² 243/2005, de 21 dez. 2005. 
Assim, analisando-se os resultados obtidos para I_Fin, sumarizados na Tabela 4, verificam-se achados consistentes com os alcançados por Mendes-Da-Silva e Magalhães Filho (2005), que encontraram correlação positiva do tamanho da firma e do retorno de suas ações (ver Modelo 1), com o nível de disclosure via website corporativo. Ressalte-se que esta pesquisa foi realizada com dados relativos a um período diferente dos utilizados por Mendes-Da-Silva e Magalhães Filho (2005), os quais consideraram todas as categorias com a mesma importância.

Observando-se os parâmetros estimados para o Modelo 2 (que adiciona a liquidez das ações em bolsa), nota-se que a liquidez das ações parece exercer influência sobre I_Fin, via website corporativo. Então, mantidas as demais condições inalteradas, quanto maior a liquidez dos papéis negociados pela empresa, maior a quantidade de informações financeiras sobre a empresa disponibilizada voluntariamente. Esse resultado não é consistente com os argumentos apresentados por Amihud e Mendelson (1988, p. 6), segundo os quais, as empresas cujos títulos demonstram baixos níveis de liquidez têm um incentivo adicional para assumir um comportamento de maior disclosure, buscando reduzir o retorno exigido pelos investidores e, por extensão, aumentar o valor da firma. O acréscimo dessa variável no modelo aumentou a importância e o nível de significância de Retn, enquanto reduziu a importância e a significância de $\operatorname{lnTamf}$. Pode-

Tabela 4 - Parâmetros estimados para o Índice de Disclosure financeira (I_Fin)

\begin{tabular}{|c|c|c|c|c|c|c|}
\hline & VARIÁVEIS INDEPENDENTES & MODELO 1 & MODELO 2 & MODELO 3 & MODELO 4 & MODELO 5 \\
\hline \multirow{6}{*}{$s$} & (Constant) & $\begin{array}{c}-724.475 * * * \\
(-6.221)\end{array}$ & $\begin{array}{c}-617.186 * * * \\
(-4.768)\end{array}$ & $\begin{array}{c}-628.579 * * * \\
(-4.783)\end{array}$ & $\begin{array}{c}-578.870 * * * \\
(-4.105)\end{array}$ & $\begin{array}{c}-447.738 * * * \\
(-3.173)\end{array}$ \\
\hline & Alavancagem & $\begin{array}{c}.328 \\
(1.125)\end{array}$ & $\begin{array}{c}.314 \\
(1.084)\end{array}$ & $\begin{array}{c}.294 \\
(1.006)\end{array}$ & $\begin{array}{c}.304 \\
(1.053)\end{array}$ & $\begin{array}{c}.486^{*} \\
(1.714)\end{array}$ \\
\hline & Retorno anual das ações & $\begin{array}{c}.497^{* * *} \\
(2.599)\end{array}$ & $\begin{array}{l}.519 * * * \\
(2.730)\end{array}$ & $\begin{array}{l}.528^{* * *} \\
(2.761)\end{array}$ & $\begin{array}{c}.377^{*} \\
(1.791)\end{array}$ & $\begin{array}{c}.306 \\
(1.498)\end{array}$ \\
\hline & Ln do tamanho da empresa & $\begin{array}{c}68.145^{* * *} \\
(9.785)\end{array}$ & $\begin{array}{c}59.962 * * * \\
(7.297)\end{array}$ & $\begin{array}{c}59.799 * * * \\
(7.256)\end{array}$ & $\begin{array}{c}55.231 * * * \\
(6.339)\end{array}$ & $\begin{array}{c}45.986 * * * \\
(5.219)\end{array}$ \\
\hline & Retorno do ativo total & $\begin{array}{c}-.590 \\
(-1.126)\end{array}$ & $\begin{array}{l}-.473 \\
(-.901)\end{array}$ & $\begin{array}{l}-.455 \\
(-.864)\end{array}$ & $\begin{array}{l}2.462^{*} \\
(1.730)\end{array}$ & $\begin{array}{l}2.374^{*} \\
(1.729)\end{array}$ \\
\hline & $\begin{array}{l}\text { Logaritmo natural do tempo de } \\
\text { listagem da firma (em anos) }\end{array}$ & $\begin{array}{c}-13.899 \\
(-.667)\end{array}$ & $\begin{array}{l}-15.536 \\
(-.750)\end{array}$ & $\begin{array}{l}-14.802 \\
(-.711)\end{array}$ & $\begin{array}{l}-21.332 \\
(-.979)\end{array}$ & $\begin{array}{l}-25.335 \\
(-1.204)\end{array}$ \\
\hline \multirow{6}{*}{ 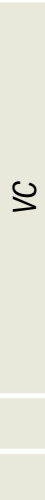 } & Liquidez das ações em bolsa & & $\begin{array}{c}23.561 * \\
(1.842)\end{array}$ & $\begin{array}{c}24.642 * \\
(1.899)\end{array}$ & $\begin{array}{l}21.377 \\
(1.649)\end{array}$ & $\begin{array}{c}25.159 * * \\
(2.004)\end{array}$ \\
\hline & Concentração do poder de voto & & & $\begin{array}{c}2.257 \times 10^{-3} \\
(.544)\end{array}$ & $\begin{array}{c}1.040 \times 10^{-3} \\
(.244)\end{array}$ & $\begin{array}{c}5.690 \times 10^{-4} \\
(.138)\end{array}$ \\
\hline & Q de Tobin & & & & $\begin{array}{l}36.235 \\
(1.484)\end{array}$ & $\begin{array}{l}25.819 \\
(1.087)\end{array}$ \\
\hline & Governança diferenciada & & & & & $\begin{array}{c}105.524 * * * \\
(3.492)\end{array}$ \\
\hline & $\mathrm{R}^{2}$ & 0,408 & 0,420 & 0,421 & 0,449 & 0,491 \\
\hline & $\mathrm{R}^{2}$ Ajustado & 0,390 & 0,399 & 0,396 & 0,419 & 0,460 \\
\hline
\end{tabular}

Nota: Esta tabela sumariza os principais resultados obtidos para os cinco modelos testados para explicar o comportamento de disclosure geral da firma via website (I_Fin), variável dependente. No Modelo 1 consideram-se apenas as variáveis de interesse para testar as hipóteses adotadas na pesquisa (Alav, Retn, InTamf, Roa, InTemp). Do Modelo 2 até o Modelo 5, foram inseridas progressivamente no modelo principal, a fim de verificar-se se as significâncias anteriormente encontradas se manteriam após a introdução das variáveis de controle ( Liqb, Hpod, Q, e Ngc). A estatística t está entre parênteses. As marcações ***, **, e *; expressam nível de significância de 1\%, 5\%, e 10\%, respectivamente. As variáveis independentes estão definidas na Tabela 3, enquanto as dependentes estão descritas no início da seção 4. 
se perceber que o acréscimo de uma unidade das variáveis de controle, apresentado na sequência dos modelos de 2 a 5 co, altera o nível de importância e significância de cada variável.

No Modelo 5, obteve-se o maior coeficiente de determinação $\mathrm{R}^{2}$ ajustado (46\%). Nesse estudo, Mendes-DaSilva (2006) assumiu que as categorias de informações financeiras, bem como as de governança mais frequentemente disponibilizadas, deveriam ser as mais relevantes para os usuários. No entanto, ao menos à luz da opinião dos agentes aqui consultados, essa premissa não parece razoável. Isto é, conforme ilustraram as Figuras 1 e 2, as categorias mais representativas para os respondentes parecem não alcançar um nível de disseminação adequado. Por outro lado, a diferença entre a relevância para usuários e a disponibilização por parte das empresas, em se tratando de categorias menos relevantes, parece ser menor.

No Modelo 5, algumas variáveis perdem importância na explicação do modelo (lnTamf), quando comparadas ao Modelo 1, e outras até mesmo deixam de ser significantes (i.e. Retn). A variável de interesse lnTamf, apesar da perda da importância que tinha no Modelo 1 , permanece significante a $1 \%$ em todos os modelos, consistindo no resultado mais robusto de todos.

Com se pode perceber na Tabela 5, que resume o resultado dos efeitos das variáveis independentes sobre I_Gov, os resultados são semelhantes aos encontrados na Tabela 4, em termos de significância e efeito no grau de explicação das variáveis significantes, à medida que

Tabela 5 - Parâmetros estimados para o Índice de Disclosure de Governança (I_Gov)

\begin{tabular}{|c|c|c|c|c|c|c|}
\hline & VARIÁVEIS INDEPENDENTES & MODELO 1 & MODELO 2 & MODELO 3 & MODELO 4 & MODELO 5 \\
\hline \multirow{6}{*}{$s$} & (Constant) & $\begin{array}{c}-609.505^{* * *} \\
(-5.171)\end{array}$ & $\begin{array}{c}-518.725^{* * *} \\
(-3.947)\end{array}$ & $\begin{array}{c}-509.778^{* * *} \\
(-3.819)\end{array}$ & $\begin{array}{c}-516.626 * * * \\
(-3.566)\end{array}$ & $\begin{array}{c}-385.994 * * * \\
(-2.656)\end{array}$ \\
\hline & Alavancagem & $\begin{array}{l}.122 \\
(.414)\end{array}$ & $\begin{array}{l}.110 \\
(.374)\end{array}$ & $\begin{array}{l}.125 \\
(.422)\end{array}$ & $\begin{array}{c}.135 \\
(.455)\end{array}$ & $\begin{array}{c}.316 \\
(1.082)\end{array}$ \\
\hline & Retorno anual das ações & $\begin{array}{l}.539 * * * \\
(2.788)\end{array}$ & $\begin{array}{c}.558 * * * \\
(2.891)\end{array}$ & $\begin{array}{l}.551^{* * *} \\
(2.837)\end{array}$ & $\begin{array}{l}.476 * * \\
(2.201)\end{array}$ & $\begin{array}{c}.405^{*} \\
(1.927)\end{array}$ \\
\hline & Ln do tamanho da empresa & $\begin{array}{c}53.257^{* * *} \\
(7.555)\end{array}$ & $\begin{array}{c}46.333 * * * \\
(5.553)\end{array}$ & $\begin{array}{c}46.462 * * * \\
(5.550)\end{array}$ & $\begin{array}{c}45.131 * * * \\
\quad(5.042)\end{array}$ & $\begin{array}{c}35.921 * * * \\
(3.959)\end{array}$ \\
\hline & Retorno do ativo total & $\begin{array}{c}-.306 \\
(-.576)\end{array}$ & $\begin{array}{c}-.207 \\
(-.388)\end{array}$ & $\begin{array}{l}-.220 \\
(-.412)\end{array}$ & $\begin{array}{c}1.472 \\
(1.007)\end{array}$ & $\begin{array}{l}1.385 \\
(.980)\end{array}$ \\
\hline & $\begin{array}{l}\text { Logaritmo natural do tempo de } \\
\text { listagem da firma (em anos) }\end{array}$ & $\begin{array}{l}-8.072 \\
(-.382)\end{array}$ & $\begin{array}{l}-9.458 \\
(-.450)\end{array}$ & $\begin{array}{l}-10.035 \\
(-.475)\end{array}$ & $\begin{array}{l}-15.603 \\
(-.697)\end{array}$ & $\begin{array}{l}-19.591 \\
(-.904)\end{array}$ \\
\hline \multirow{6}{*}{ 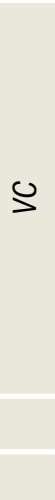 } & Liquidez das ações em bolsa & & $\begin{array}{l}19.936 \\
(1.535)\end{array}$ & $\begin{array}{l}19.087 \\
(1.448)\end{array}$ & $\begin{array}{l}14.283 \\
(1.072)\end{array}$ & $\begin{array}{l}18.051 \\
(1.396)\end{array}$ \\
\hline & Concentração do poder de voto & & & $\begin{array}{c}-1.772 \times 10^{-3} \\
(-.421)\end{array}$ & $\begin{array}{c}-2.781 \times 10^{-3} \\
(-.634)\end{array}$ & $\begin{array}{c}-3.250 \times 10^{-3} \\
(-.766)\end{array}$ \\
\hline & Q de Tobin & & & & $\begin{array}{c}47.096 * \\
(1.877)\end{array}$ & $\begin{array}{l}36.721 \\
(1.502)\end{array}$ \\
\hline & Governança diferenciada & & & & & $\begin{array}{c}105.121 * * * \\
(3.378)\end{array}$ \\
\hline & $\mathrm{R}^{2}$ & 0,299 & 0,309 & 0,310 & 0,340 & 0,387 \\
\hline & $\mathrm{R}^{2}$ Ajustado & 0,277 & 0,283 & 0,280 & 0,305 & 0,350 \\
\hline
\end{tabular}

Nota: Esta tabela sumariza os principais resultados obtidos para os cinco modelos testados para explicar o comportamento de disclosure geral da firma via website (I_Gov), variável dependente. No Modelo 1, consideram-se apenas as variáveis de interesse para testar as hipóteses adotadas na pesquisa ( Alav, Retn, InTamf, Roa, InTemp). Do Modelo 2 até o Modelo 5, foram inseridas progressivamente no modelo principal, a fim de verificar se as significâncias anteriormente encontradas se manteriam após a introdução das variáveis de controle (Liqb, Hpod, Q, e $\mathrm{Ngc}$ ). A estatística t está entre parênteses. As marcações ***, **, e *; expressam nível de significância de 1\%, 5\%, e 10\%, respectivamente. As variáveis independentes estão definidas na Tabela 3, enquanto as dependentes estão descritas no início da seção 4. 
se avança do Modelo 1 ao Modelo 5. Ou seja, as variáveis independentes apresentam efeitos semelhantes nas variáveis dependentes: I_Fin e I_Gov. Como na Tabela 4, o índice de $\ln$ Tamf permanece significante a $1 \% \mathrm{em}$ todos os modelos, apesar de diminuir seu poder de explicação. De forma similar, Retn diminui seu poder de explicação e o grau de significância, como ocorreu na Tabela 4.

Em se tratando de I_Disc, cujos parâmetros da regressão se encontram resumidos na Tabela 6, nota-se que Retn, juntamente com $\ln T a m f$, são as variáveis mais representativas para explicar I_Disc, ao menos segundo a forma como foram definidas e operacionalizadas nesta pesquisa. Nos cinco modelos testados, $\ln$ Tamf foi significativa a $1 \%$. Segundo os parâmetros estimados para essas duas variáveis independentes, quanto maior o retorno anual das ações, e quanto maior seu tamanho, caeteris paribus, maior tende a ser a quantidade de informações de interesse do mercado disponibilizadas pelo website corporativo. Esse resultado é consistente com os obtidos por Mendes-Da-Silva e Magalhães Filho (2005) e por MendesDa-Silva (2006).

\section{CONSIDERAÇÕES FINAIS}

Tendo em vista recentes os escândalos financeiros ocorridos em alguns mercados ao redor do mundo, a restauração da confiança da opinião pública na administração das grandes empresas tem ocupado lugar de destaque

Tabela 6 - Parâmetros estimados para o Îndice de Disclosure Geral (I_Disc)

\begin{tabular}{|c|c|c|c|c|c|c|}
\hline & VARIÁVEIS INDEPENDENTES & MODELO 1 & MODELO 2 & MODELO 3 & MODELO 4 & MODELO 5 \\
\hline \multirow{6}{*}{ 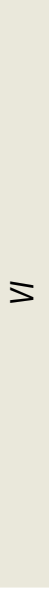 } & (Constant) & $\begin{array}{c}-1333.980 * * * \\
(-6.118)\end{array}$ & $\begin{array}{c}-1135.910 * * * \\
(-4.685)\end{array}$ & $\begin{array}{c}-1138.357 * * * \\
(-4.621)\end{array}$ & $\begin{array}{c}-1095.496 * * * \\
(-4.122)\end{array}$ & $\begin{array}{c}-833.732 * * * \\
(-3.152)\end{array}$ \\
\hline & Alavancagem & $\begin{array}{l}.450 \\
(.825)\end{array}$ & $\begin{array}{l}.424 \\
(.782)\end{array}$ & $\begin{array}{l}.419 \\
(.766)\end{array}$ & $\begin{array}{l}.439 \\
(.807)\end{array}$ & $\begin{array}{c}.802 \\
(1.509)\end{array}$ \\
\hline & Retorno anual das ações & $\begin{array}{c}1.036 * * * \\
(2.895)\end{array}$ & $\begin{array}{c}1.077^{* * *} \\
(3.025)\end{array}$ & $\begin{array}{c}1.079 * * * \\
(3.010)\end{array}$ & $\begin{array}{l}.854^{* *} \\
(2.150)\end{array}$ & $\begin{array}{c}.711^{*} \\
(1.858)\end{array}$ \\
\hline & Ln do tamanho da empresa & $\begin{array}{c}121.402^{* * *} \\
(9.310)\end{array}$ & $\begin{array}{c}106.296 * * * \\
(6.906)\end{array}$ & $\begin{array}{c}106.260 * * * \\
(6.878)\end{array}$ & $\begin{array}{c}100.362^{* * *} \\
(6.113)\end{array}$ & $\begin{array}{c}81.907^{* * *} \\
(4.959)\end{array}$ \\
\hline & Retorno do ativo total & $\begin{array}{l}-.896 \\
(-.913)\end{array}$ & $\begin{array}{l}-.679 \\
(-.691)\end{array}$ & $\begin{array}{l}-.676 \\
(-.684)\end{array}$ & $\begin{array}{c}3.934 \\
(1.467)\end{array}$ & $\begin{array}{c}3.758 \\
(1.461)\end{array}$ \\
\hline & $\begin{array}{l}\text { Logaritmo natural do tempo de } \\
\text { listagem da firma (em anos) }\end{array}$ & $\begin{array}{l}-21.970 \\
(-.563)\end{array}$ & $\begin{array}{l}-24.994 \\
(-.644)\end{array}$ & $\begin{array}{l}-24.836 \\
(-.637)\end{array}$ & $\begin{array}{l}-36.936 \\
(-.899)\end{array}$ & $\begin{array}{l}-44.926 \\
(-1.138)\end{array}$ \\
\hline \multirow{6}{*}{$\checkmark$} & Liquidez das ações em bolsa & & $\begin{array}{l}43.497^{*} \\
(1.815)\end{array}$ & $\begin{array}{l}43.729 * \\
(1.798)\end{array}$ & $\begin{array}{l}35.661 \\
(1.459)\end{array}$ & $\begin{array}{l}43.210 * \\
(1.836)\end{array}$ \\
\hline & Concentração do poder de voto & & & $\begin{array}{l}4.847 \times 10^{-4} \\
\quad(.062)\end{array}$ & $\begin{array}{c}-1.741 \times 10^{-3} \\
(-.216)\end{array}$ & $\begin{array}{c}-2.681 \times 10^{-3} \\
(-.347)\end{array}$ \\
\hline & Q de Tobin & & & & $\begin{array}{l}83.331 * \\
(1.811)\end{array}$ & $\begin{array}{l}62.540 \\
(1.405)\end{array}$ \\
\hline & Governança diferenciada & & & & & $\begin{array}{l}210.645^{* * *} \\
\quad(3.718)\end{array}$ \\
\hline & $\mathrm{R}^{2}$ & 0,387 & 0,400 & 0,400 & 0,429 & 0,478 \\
\hline & $\mathrm{R}^{2}$ Ajustado & 0,368 & 0,377 & 0,373 & 0,398 & 0,446 \\
\hline
\end{tabular}

Nota: Esta tabela sumariza os principais resultados obtidos para os cinco modelos testados para explicar o comportamento de disclosure geral da firma via website (I_Disc), variável dependente. No Modelo 1, consideram-se apenas as variáveis de interesse para testar as hipóteses adotadas na pesquisa (Alav, Retn, InTamf, Roa, InTemp). Do Modelo 2 até o Modelo 5, foram inseridas progressivamente no modelo principal, a fim de verificar se as significâncias anteriormente encontradas se manteriam após a introdução das variáveis de controle (Liqb, Hpod, Q, e Ngc). A estatística t está entre parênteses. As marcações $* * *, * *$, e *; expressam nível de significância de $1 \%, 5 \%$, e $10 \%$, respectivamente. As variáveis independentes estão definidas na Tabela 3, enquanto as dependentes estão descritas no início da seção 4. 
em discussões, tanto no âmbito acadêmico quanto no empresarial. Desse modo, o aumento da transparência e o oferecimento de informações acerca das estruturas de administração da firma podem ser um meio de atingir esse objetivo. Informações de alta qualidade e relevância são preponderantes para o exercício das boas práticas de governança corporativa. O aumento da demanda por maior transparência acerca das práticas de governança pode criar incentivos para o abandono de antigas práticas e a escolha de novos procedimentos que levem às melhores práticas de governança. Ademais, existe a expectativa de que, nos próximos meses, a economia brasileira ingresse no seleto grupo dos países vistos como investment grade, o que deve ter como principal consequência a intensificação do fluxo de recursos estrangeiros no mercado nacional.

Assim, diante do crescente uso da web no Brasil e no mundo, o objetivo deste estudo foi verificar a existência de associações entre características das firmas e a disseminação voluntária de informações de interesse dos investidores em websites corporativos, tomando-se como referência as empresas não financeiras listadas na Bovespa, bem como a relevância das categorias de informações corporativas para o mercado. Preliminarmente, é importante ressaltar que ainda não existem regras ou orientações explícitas acerca da utilização da internet como meio de disseminação de informações de interesse do investidor no âmbito nacional.

Os principais resultados alcançados neste estudo são dois. Primeiro, consistentemente com a literatura internacional (MARSTON e LEOW, 1998) e a já existente no âmbito nacional, quanto maior a firma e quanto maior o retorno anual das ações da empresa, maior é a soma de informações disseminadas no website corporativo. Um segundo resultado a ser destacado é que, apesar de não existir padronização quanto ao uso da internet na comunicação com investidores, as empresas de governança corporativa diferenciada (Novo Mercado, Níveis 1 e 2) apresentaram uma soma de informações relevantes, significativamente superior às demais. É conveniente ressaltar que as categorias de informações corporativas mais relevantes, no julgamento das agências de rating e das corretoras de valores mobiliários que operam no mercado brasileiro, parecem não alcançar um nível de disseminação adequado, segundo a demanda desses intermediários de informações corporativas.

Tanto a Bovespa como a CVM têm-se limitado a apenas incentivar o uso voluntário da internet para atividades de RI, não havendo ainda atos normativos a esse respeito. Esta última, em suas instruções mais recentemente fornecidas às empresas, recomenda o atendimento aos usuários das informações corporativas, por meio do arquivamento nas autoridades reguladoras e nas Bolsas. Assim, canais de comunicação mais próximos dos investidores, como os press releases para agências de notícias e entrevistas, e especialmente os websites corporativos, fazem parte de esforços predominantemente voluntários.

Em suma, os resultados obtidos por Isenmann (2000), Kolk (1999) e Jones, Alabaster e Hetherington (1999), os quais apontam a mídia impressa como principal meio de comunicação da firma com o mercado (no contexto latino-americano), não parecem ter sofrido mudanças na direção de uma maior utilização de meios eletrônicos, os quais são comprovadamente menos dispendiosos. Diante desse quadro, parece que, segundo o entendimento das empresas de capital aberto, com ações em bolsa no Brasil, o custo da perda de confidencialidade não é justificado pela redução no custo de manutenção da empresa em bolsa, especialmente em se tratando das despesas com publicações.

Dessa forma, ainda não se tem conhecimento de normativos específicos sobre a divulgação de informações pelas empresas com o uso da internet. As questões anteriormente colocadas juntam-se a outras e sugerem um campo promissor para estudos futuros, destacadamente aqueles que viabilizem a criação de novos modelos teóricos ou empíricos, considerando um número cada vez maior de variáveis, uma vez que as organizações estão se tornando mais complexas, tendo em vista sua inserção em mercados cada vez mais competitivos e exigentes, ávidos por informação.

Este estudo, a partir de suas escolhas metodológicas, possui algumas limitações, dentre as quais ressalta-se a verificação da existência de associações entre características corporativas e a disseminação voluntária de informações de interesse do investidor pela internet, considerando apenas as companhias não financeiras listadas na Bovespa, em um dado período. Diante da emergência do tema aqui abordado para o mercado de capitais nacional, alguns aspectos podem ser citados como motivo de pesquisas futuras:

a) identificar as razões pelas quais algumas empresas ainda não utilizam a internet no relacionamento com o investidor;

b) verificar, no âmbito nacional, segundo a opinião dos investidores e demais stakeholders, o perfil da demanda por informações relativas às empresas, pela web;

c) verificar a validade das informações financeiras divulgadas na internet;

d) discutir o aumento do uso da internet no relaciona- 
mento com investidores no âmbito das empresas brasileiras e suas implicações nos padrões de relatórios contábeis;

e) investigar as associações entre investimento em Tecnologia de Informação e disseminação de informações financeiras na internet;

f) analisar os impactos da disseminação voluntária de informações no custo dos capitais próprio e de terceiros utilizados pelas empresas;

g) replicar este estudo em outros ambientes institucionais, em diferentes períodos de tempo;

h) ainda que haja aparente unanimidade na ideia de que a exploração da internet pode viabilizar um excelente canal de comunicação, este estudo pode servir de ponto de partida para outras formas de comunicação corporativa para RI.

\section{REFERÊNCIAS}

AITKEN, M; HOOPER, C; PICKERING, J. Determinants of voluntary disclosure of segment information: a re-examination of the role of diversification strategy. Accounting and Finance, v. 37, n. 1, p. 89-109, 1997.

AMIHUD, Y; MENDELSON, H. Liquidity and asset prices: financial management implications. Financial Management, v. 17, n. 1, p. 5-15, 1988.

ASHBAUGH, H; JOHNSTONE, K. M; WARFIELD, T. D. Corporate reporting on the internet. Accounting Horizons, v. 13, n. 3, p. 241-257, 1999.

BOTOSAN, C. A. Disclosure level and the cost of equity capital. The Accounting Review, v. 71, n. 3, p. 323-349, 1997.

BRENNAN, N; HOURIGAN, D. Corporate reporting on the internet by irish companies. The Irish Accounting Review, v. 7, n. 1, p. 37-68, 2000

BURLAMAQUI, L; PROENÇA, A. Inovação, recursos e comprometimento: em direção a uma teoria estratégica da firma. Revista Brasileira de Inovação, v. 2, n. 1, p. 79-110, 2003.

CHUNG, K. H; PRUITT, S. W. A simple approximation of Tobin'sq. Financial Management, v. 23, n. 3, p. 70-74, 1994.

CLARKSON, P. M; KAO, J. L; RICHARDSON, G. D. The voluntary inclusion of forecasts in the MD\&A section of annual reports. Contemporary Accounting Research, v. 11, n. 1, p. 423-450, 1994.

COX, C. T. Further evidence on the representativeness of management earning forecasts. The Accounting Review, v. 60, n. 4, p. 692-701, 1985.

CRAVEN, B. N; MARSTON, C. L. Financial reporting on the internet by leading UK companies. European Accounting Review, v. 8. n. 2, p. $321-$ 333, 1999
DEBRECENY, R; GRAY, G. Financial reporting on the Internet and the external audit. The European Accounting Review, v. 8, n. 2, p. 335-350, 1999.

DYCK, A; ZINGALES, L. The Corporate Governance Role of the Media. Working Paper 9309. National Bureau of Economic Research, Cambridge, Massachusetts, 2002.

ETTREDGE, M; RICHARDSON, V; SCHOLZ, S. Dissemination of information for investors at corporate web sites. Journal of Accounting and Public Policy, v. 21, p. 357-369, 2002.

GOWTHORPE, C; AMAT, O. External reporting of accounting and financial internation via the internet in Spain. The European Accounting Review, v. 8, n. 2, p. 365-371, 1999.

GRAY, G. L; DEBRECENY, R. S. Corporate reporting on the internet: opportunities and challenges. In: ASIAN-PACIFIC CONFERENCE ON INTERNATIONAL ACCOUNTING ISSUES, $7^{\text {th }}, 1997$, Bangkok, Proceedings. Bangkok: Iai, 1997.

HAIR, J. F; ANDERSON, R. E; TATHAM, R. L; BLACK, W. C. Multivariate Data Analysis, $5^{\text {th }}$ ed. Upper Saddle River: Prentice Hall, 1998.

HANIFFA, R. M; COOKE, T. E. Culture, corporate governance and disclosure in Malaysian corporations. Abacus, v. 38, n. 3, p. 317-349, 2002.

HELDIN, P. The internet as a vehicle for investor relations: the Swedish case. European Accounting Review, v. 8, n. 2, p. 373-379, 1999.

HOSSAIN, M; BERERA, M; RAHMAN, A. Voluntary disclosure in the annual reports of New Zealand companies. Journal of International Financial Management and Accounting, v. 6, n. 1, p. 69-87, 1995.

ISENMANN, R; LENZ, C. System of technical benefits using the internet for corporate environmental reporting. The 2000 Business Strategy and the Environment Conference. ERP Environment (Ed). Shipley: ERP, 2000. p. 203-210.

ISENMANN, R; LENZ, C. Internet-based integration of financial and environmental reporting: step towards sustentainability reporting. The 2001 Business Strategy and Environment Conference. Sept. $10^{\text {th }}$ and $11^{\text {th }}$, University of Leeds, UK, ERP Environment (Ed). Shipley: ERP, 2001. p. 169-178.

JENSEN, M. C; MECKLING, W. Theory of firm: managerial behavior, agency costs and ownership structure. Journal of Financial Economics, v. 3, n. 4, p. 305-360, 1976.

JONES, K; ALABASTER, T; HETHERINGTON, K. Internet-Based Environmental Reporting: Current Trend, 1999.

KOLK, A. The internet as a green management tool. Harvard Business Review, v. 6, n. 3, p. 307-316, 1999

KORETO, R. J. If you build it, will they come? Journal of Accountancy, v. 184, n. 1, p. 84-90, 1997. 
LA PORTA e outros. Law and finance. Journal of Political Economy, v. 106, n. 6, p. 1113-1155, 1998.

LANG, M; LUNDHOLM, R. Cross-sectional determinants of analyst ratings of corporate disclosures. Journal of Accounting Research, v. 31, n. 2, p. 246-271, 1993.

LEFTWICH, R; WATTS, R; ZIMMERMAN, J. Voluntary corporate disclosure: the case of interim reporting. Journal of Accounting Research, v. 19, p. $50-77,1981$.

LEV, B; PENMAN, S. Voluntary forecast disclosure, nondisclosure and stock prices. Journal of Accounting Research, v. 28, n. 1, p. 49-76, 1990.

LITAN, R. E; WALLISON, P. J. The GAAP Gap: Corporate Disclosure in the Internet Age. Washington: AEI-Brookings Joint Center for Regulatory Studies; La Vergne, TN, 2000.

LYMER, A; TALlBERG, A. Corporate reporting and the internet - A Survey and commentary on the use of the WWW in corporate reporting in the UK and Finland. In: ANNUAL CONGRESS OF THE EUROPEAN ACCOUNTING ASSOCIATION, 20 ${ }^{\text {th }}$, 1997, Graz, Proceedings. Graz: EAA, 1997.

MARSTON, C; LEOW, C. Y. Financial reporting on the internet by leading UK companies. In: EUROPEAN ACCOUNTING ASSOCIATION CONFERENCE, 21 1' st 1998, Belgium, Proceedings. Belgium: EAA, 1998.

MCKINNON, J; DALIMUNTHE, L. Voluntary disclosure of segment information by Australian diversified companies. Accounting and Finance, v. 33, n. 1, p. 33-50, 1993.

MEEK, G; ROBERTS, C; GRAY, S. Factors influencing voluntary annual report disclosures by U.S., U.K. and continental European multinational corporations. Journal of International Business Studies, v. 26, n. 3, p. 555572, 1995.

MENDES-DA-SILVA, W. Disseminação voluntária de informações financeiras e práticas de governança corporativa em websites corporativos: um estudo empírico com empresas listadas na Bovespa. In: ENCONTRO DA ASSOCIAÇÃO NACIONAL DOS PROGRAMAS DE PÓS-GRADUAÇÃO EM ADMINISTRAÇÃO, 30. 2006, Salvador, Anais. Salvador: Anpad, 2006.

MENDES-DA-SILVA, W; MAGALHÃES FILHO, P. A. O. Determinantes da disseminação voluntária de informações financeiras na internet. RAEeletrônica, v. 4, n. 2, p. 1-23, 2005a.
MENDES-DA-SILVA, W; MAGALHÃES FILHO, P. A. O. Verificando associações entre governança corporativa e governança de tecnologia de informação: uma análise empírica com indústrias brasileiras. In: ENCONTRO DA ASSOCIAÇÃO NACIONAL DOS PROGRAMAS DE PÓS-GRADUAÇÃO EM ADMINISTRAÇÃO, 29. 2005, Brasília, Anais. Brasília: Anpad, 2005b.

MITCHELL, J; CHIA, C; LOH, A. Voluntary disclosure of segment information: further Australian evidence. Accounting and Finance, v. 35, n. 2 p. 1-16, 1995.

REPORT OF THE HIGH LEVEL GROUP OF COMPANY LAW EXPERTS Disponível em: http://www.law.rug.ac.be/fli/WP/takeover\%20bids.pdf 2002. Acesso em: 15.02.2005.

ROCCA, C. A; CARVALHO, A. G. Mercado de capitais e o financiamento das empresas abertas. Relatório de pesquisa. São Paulo: FIPE/ABRASCA, 1999.

ROCHA, C. F. P; PROCIANOY, J. L. Disclosure das companhias abertas brasileiras: um estudo exploratório. Gestão.Org, v. 2, n. 3, p. 169-182, 2004.

SCHUSTER, P; O'CONNELL, V. The trend toward voluntary corporate disclosure. Management Accounting Quarterly, v. 7, n. 2, p. 1-9, 2006.

SHEEHY, D. E.; TRITES, G. D. Canadian Accountant's Guide to the Internet. Toronto: Carswell, 1997.

WACKER, J. G. A definition of theory: research guidelines for different theory-building research methods in operations management. Journal of Operations Management, v. 16, n. 4, p. 361-385, 1998.

WAGENHOFER, A. Economic consequences of internet financial reporting. Schmalenbach Business Review, v. 55, n. 4, p. 263-279, 2003.

WAYMIRE, G. Earnings volatility and voluntary management forecast disclosure. Journal of Accounting Research, v. 23, n. 1, p. 268-295, 1985.

WORLD BANK. Investor Opinion Survey on Corporate Governance. London: Mckinsey \& Company, June 2000

ZINGALES, L. In search of new foundations. Journal of Finance, v. 55, n. 4, p. 1623-1653, 2000. 